\title{
Factors Associated with the Occurrence of
Cyanotic Spells in Tetralogy of Fallot Patients
}

\author{
Teddy Ontoseno
}

\author{
(Department of Child Health, Medical School, \\ University of Airlangga/Dr. Soetomo Hospital, Surabaya)
}

ABSTRACT A study was carried out on 114 tetralogy of Fallot patients attending the Department of Child Health, Medical School, University of Airlangga/Dr. Soetomo Hospital between 1 January 1988 to 31 December 1992 . On such as cyanotic spells, $4(4.93 \%)$ teria where $52(64.2 \%)$ were cases with comple individuals without complications acted among them had brain abscesses. Twent hematocrit, MCHC and onset of symptoms beas controls. Age, sex, nutritional status, hing the multiple regression logistic. It has been shown that relative anemia, polycythemia and the age of 2-5 years contributed to the onset of cyanotic spells, respectively, $R=0.3171$ and $p=0.0004 ; R=0.2220$ and $p=$ $0.0073 ; \mathrm{R}=0.1363$ and $\mathrm{p}=0.00465$. There fore, in conventional treatment of tetralogy of $0.0073 ; \mathrm{R}=0.1363$ and $\mathrm{p}=0.00465$. There fore, in convention to observe these risk factors in order to avoid complications
Fallot patients it is essential to obse for the waiting list for surgery.
and to improve the quality of life in these patients who are on the wa [Paediatr Indones 1995; 35:227-230]

\section{Introduction}

Tetralogy of Fallot is the most commonly found type of cyanotic congenital heart disease.' Open cardiac surgery is the only definite treatment of patients with tetralogy of Fallot; ${ }^{2}$ however, complex and sophisticated equipment and facilities are

Accepted for publication: July 30, 1995 Author's address: Teddy Ontoseno, MD. Department of Child Health, Medical School. University of Airlangga, Jl. Darmohusodo, Surabaya, Indonesia essential for this kind of expensive surgery, besides great experience and a good team-work among the specialists involved $^{3,4}$ Thus, not all patients have the chance to be operated on; just few medical centers are able to perform this kind of surgery. Unfortunately, not all operated patients show the expected results. ${ }^{5.6}$ On the other hand, although new cases are diagnosed every year, the majority of these patients come from a low socioeconomic class, thus resulting in many 
unoperated tetralogy of Fallot patients. Furthermore, some patients on the waiting list for surgery who are being treated conventionally, often develop life threatening complications, which results in in creased mortality rate and complications during surgery. ${ }^{7}$ It is essential to find factors associated with the development of complications in patients who are being treated medically. If these factors can be controlled it would be possible to prevent these complications and a better quality of life can be expected for these patients while waiting for surgery. ${ }^{8}$

\section{Methods}

A case-control hospital-based study was carried out on tetralogy of Fallot patients from January 1988 to December 1992, consisting of outpatients and in-patients of the Division of Cardiology, Department of Child Health, Dr. Soetomo Hospital, Surabaya. Patients included in this study comprised all echocardiographically confirmed tetralogy of Fallot patients with complication, i.e., cyanotic spells which were evidenced a history of sudden deep and fast breaths which accompanied by increased cyanosis resulting in weakness, to fainting spells and convulsions, or those suffering from brain abscess indicated by fever, leukocytosis, increased in tracranial pressure, or evidence of brain abscess on skull x-ray and CT-Scan. Tetralogy of Fallot patients without complications served as controls.

Laboratory criteria were as follows: polycythemia was defined as hematocrit $\geq$ $65 \%$ with hemoglobin level $\geq 18 \mathrm{~g} / \mathrm{dl}$, relative anemia was defined as $\mathrm{MCHC}<30 \%$.
The age was based on the birth certificate at the time of admittance, the nutritional status was grouped on age matched body weight according to the NCHS/WHO. The nutritional status was considered as good if it was within 2 SD from the standard, medium if 3 SD from the standard, poor if $4 \mathrm{SD}$ from the standard. The time at which the patient for the first time complained about complications was considered as the time of the first complaint.

Multiple logistic regression method was used to predict the probability of complications as a consequence of several risk factors and determine the odds ratio.

\section{Results}

The subjects consisted of 81 (71.1\%) patients fulfilling the study criteria, consisting of 47 boys and 34 girls and 29 $(35.0 \%)$ controls. Of the 81 patients, 52 $(64.2 \%)$ experienced cyanotic spells and 4 (4.9\%) had a brain abscess besides cyanotic spells. The age of the patients ranged from 3 months to 12 years with $19.8 \%$ under 2 years old, $39.5 \%$ between $2-5$ years, and $40.8 \%$ over 5 years old.

The cyanotic spells mostly occurred between $2-5$ years $(46.2 \%)$; the prevalence of the spells was higher in boys than in girls (1.26:1).

In most cases, the hemoglobin concentration was more than $18 \mathrm{~g} / \mathrm{dl}$ and $42.3 \%$ of the patients showed a hematocrit of more than $65 \%$. Brain abscess was found at the age of more than 3 years $(75 \%)$ with boy to girl ratio of $3: 1$, and hematocrit of more than $65 \%$.

A good nutritional status was found in $24.7 \%$ of the cases and only $17.3 \%$ of the cases were accompanied by cyanotic spells $25 \%$ of the cases were accompanied by brain abscess. A poor nutritional status was found in $75.3 \%$ of the cases and $82.7 \%$ suffered from cyanotic spells, $75 \%$ cases were accompanied by brain abscess.

Relative anemia was found in $51.8 \%$, of which $73.1 \%$ suffered from cyanotic spells. All brain abscess cases were accompanied by relative anemia. Polycythemia was found in $29.6 \%$ of the cases.

Hemoglobin concentration, hematocrit, relative anemia and age 2-5 years showed a significant association with cyanotic spells. As seen from the logistic regression analysis the probability of tetralogy of Fallot patients to develop cyanotic spells is:

\section{$P(X)=1+e(-3,0121+2,89 \times$ relative anemia + \\ $1+e(-3,0121+2,89 \times$ relative anemiat
$2,8678 \times$ polycythemia $x$ age $(2-5$ year $)$}

A rating of 1 point is given if the above mentioned symptoms occur and zero point if no symptoms occur. $\mathrm{P}(\mathrm{x})$ is the probability of a tetralogy of Fallot patient to develop cyanotic spell, as the exponential value or natural logarithmic value $=$ 2.718 .

\section{Discussion}

Relative anemia $(\mathrm{p}=0.0004$ and $\mathrm{r}=$ 0.3170 ) which is found in $51.9 \%$ of the patients contributed the most to cyanotic spells. The odds ratio of relative anemia was found to be 18.0769 ; thus, the risk of tetralogy of Fallot patients with relative anemia experiencing cyanotic spells is 18 times more than patients without relative anemia.

Following relative anemia, the hematocrit levels played a great role in the occurrence of cyanotic spells. The hematocrit levels showed a significant positive correlation with cyanotic spells $(\mathrm{p}=0.0073$ and $r=0.222$ ) and showed that the relative risk in the occurrence of cyanotic spells was 17.6 times greater than without polycythemia. The higher the hematocrit levels, the greater the blood viscosity and consequently resulting in an increase in disturbances of the blood flow, especially in the circulation to the brain.

It has been observed that age of the patient has a significant correlation with cyanotic spells, $2-5$ years of age $(p=$ $0.0465, r=0.1363$ and $O R=6.7864)$. At the age of $2-5$ years the relative risk of developing cyanotic spells was 6.8 times greater than the other age groups. According to child, 1991, the hemodynamic changes are evidence at 2-4 year in the form of hypoxia of various degrees. ${ }^{7}$ Ac cording to Sastroasmoro ${ }^{9}$ cyanotic spells decrease in frequency as well as intensity following the formation of blood vessel collateral at the age of 18 moths to 2 years.

Previous investigators observed that the prevalence of brain abscess was $23 \%{ }^{7}$ however, in this study it was shown to be only $4.9 \%$. This appears to be caused by the fact that many patients with a brain abscess did not visit the hospital and that this investigation was only limited to pathis ins tients aged 12 years old while the occurrence of brain abscess is mostly at the age of more than 12 years. ${ }^{7}$ No significant 
correlation was found in patients with brain abscess with other parameters, this may be caused to the relative small number of patients studied. However, it has been observed that the mean hemoglobin in patients with brain abscess was $19.4500 \pm 1.23234$ and the mean hematocrit was $68.75 \pm 4.8563$.

Sastroasmoro ${ }^{9}$ noted that the prevalence of brain abscess or CVA was higher in patients with hemoglobin and hematocrit levels of more than $18 \mathrm{gr} / \mathrm{dl}$ and $65 \%$. This is accordance with the results of this study: mean hemoglobin in the group without complications of $17.9207 \pm$ 1.7498 , and $19.4500 \pm 1.2234$ in the group with a brain abscess, and a mean hematocrit of $68.75 \pm 4.8563$.

\section{Conclusions}

From the results of the study it has been shown that relative anemia, polycythemia, and age 2-5 years are associated with the occurrence of cyanotic spells. It is possible that other factors may also be involved, however, other parameters such as platelet count, albumin concentration and nutritional status have not been studied. By using the multiple logistic analysis the probability of Tetralogy Fallot patients in developing cyanotic spells can be calculated as follows:

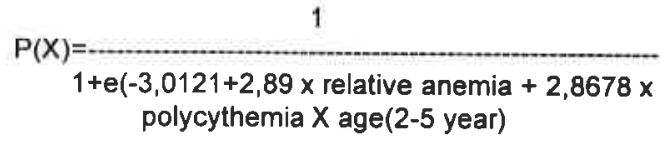

Further investigations have to be performed in order to study other risk factors which may be associated with cyanotic spells, brain abscess or other complications.

By taking the risk factors into consideration it is possible to avoid complications during the pre-operative preparations in order to obtain optimal results.

\section{References}

1. Jordan SC, Scoot O. Tetralogy of Fallot. In: Heart disease in pediatrics; 3rd ed. London: Butterworths 1989; 148-57.

2. Graham TP. When to operate on the child with congenital heart disease. Pediatr Clin North Am 1984; 31:1275.

3. Tahalele P. Permasalahan operasi jantung di RSUD Dr. Soetomo Surabaya. Warta IKABI, 1988; I: 49-53.

4. Stephenson LW, Friedman MD, Edmunds LH. Staged surgical management of tetralogy Fallot in infants. Circulation 1978; $58: 837$.

5. Prasodo AM. Cyanotic congenital heart disease without surgical intervention. Maj Kardiol Indones 1988; 3:119-23.

6. Anderson RH Macartney FJ, Shinebourne EA, Tyan M. Pediatric cardiology, Vol. 2. Edinburg: Churchill Livingstone, 1990;765-93.

7. Ontoseno T. Serangan sianosis. Continuing Education Ilmu Kesehatan Anak, 1991; 23: 91-101.

8. Jordan SC, Scott Olive. Complications of Congenital Heart Disease. Heart Diseases in Paediatrics. Third ed. Butterworths London, Boston, Singapore, Sydney, Toronto, Wellington, 1989; 262-73.

9. Sastroasmoro S, Madiyono B. Penyakit jantung bawaan sianotik dengan vaskularisasi paru berkurang. In: Markum AH .et al. eds. Buku ajar ilmu kesehatan anak, vol I. FKUI Jakarta, 1991, 577. 